\title{
Erratum to: Improvements in Spelling after QEEG-based Neurofeedback in Dyslexia: A Randomized Controlled Treatment Study
}

\author{
Marinus H. M. Breteler • Martijn Arns • \\ Sylvia Peters • Ine Giepmans • Ludo Verhoeven
}

Published online: 12 March 2010

(C) Springer Science+Business Media, LLC 2010

\section{Erratum to: Appl Psychophysiol Biofeedback (2010) 35:5-11 \\ DOI 10.1007/s10484-009-9105-2}

In the first 2010 issue of Applied Psychophysiology and Biofeedback we presented data concerning the effects of neurofeedback on various parameters of reading and spelling (Breteler et al. 2010). For spelling we reported a large effect size of 3.02. In a subsequent correspondence with prof. Daniel Brandeis (Brandeis 2010) from the University of Zürich, Switzerland, he and his co-workers pointed to an incorrect use of the data by us, using the formula of Becker (1998).

Klauer (1993) showed that the overall effect size of prepost data from an experimental and control group can be computed as $\mathrm{d}$ corr $=\mathrm{d}$ post $-\mathrm{d}$ pre.

Calculating $\mathrm{d}$ pre (using the formula calculator of Becker) with $\mathrm{m} \operatorname{expT} 1=69.1$ and s.d. expT1 $=32$ and $\mathrm{m}$

The online version of the original article can be found under doi:10.1007/s10484-009-9105-2.

M. H. M. Breteler $(\bowtie)$

EEG Resource Institute, P.O. Box 31070, 6503 CB Nijmegen, The Netherlands

e-mail: r.breteler@eegbiofeedback.nl

M. H. M. Breteler · S. Peters - I. Giepmans - L. Verhoeven Behavioural Science Institute, Radboud University Nijmegen, Nijmegen, The Netherlands

\section{Arns}

Brainclinics Diagnostics, Nijmegen, The Netherlands

S. Peters

Platform Beta Techniek, Den Haag, The Netherlands
controlT1 $=66.9$ (s.d. controlT1 $=20.9)$ leads to a pretreatment effect size of 0.08 .

Calculating d post with $\mathrm{m}$ expT2 $=80.6$ (s.d. $\operatorname{expT} 2=$ 32.2) and $\mathrm{m}$ controlT $2=70.9$ (s.d. controlT2 $=24.4$ ) leads to a posttreatment effect size of 0.34 .

So, the corrected overall effect size will be 0.26 . This was also suggested by Brandeis, using a site by Jacobs (1999).

This finding nuances the conclusions from our study. The effect of neurofeedback on spelling is still significant, but small rather than average. Therefore, we would like to add that more research is needed to arrive at more final conclusions on the effects of neurofeedback training on the learning of reading and spelling.

\section{References}

Becker, L. A. (1998). http://www.uccs.edu/ faculty/lbecker/.

Brandeis, D. (2010). Effect size in neurofeedback. Personal communication.

Breteler, M. H. M., Arns, M., Peters, S., Giepmans, I., \& Verhoeven, L. (2010). Improvements in spelling after QEEG-based neurofeedback in dyslexia: A randomized controlled treatment study. Applied Psychophysiology and Biofeedback, 35, 5-11.

Jacobs, B. (1999). http://www.phil.uni-sb.de/\%7Ejakobs/seminar/vpl/ bedeutung/eskorr.htm.

Klauer, K. (1993). Thought training for adolescents. A program for intellectual challenge. Manual. [Denktraining für Jugendliche. Ein Programm zur intellektuellen Förderung.Handanweisung.] Göttingen: Hogrefe. 